\title{
Perspectives in genetic counseling for spinal muscular atrophy in the new therapeutic era: early pre-symptomatic intervention and test in minors
}

\author{
Clara Serra-Juhe ${ }^{1} \cdot$ Eduardo F. Tizzano ${ }^{1,2}$
}

Received: 13 August 2018 / Revised: 5 March 2019 / Accepted: 7 March 2019 / Published online: 3 May 2019

(c) The Author(s) 2019. This article is published with open access

\begin{abstract}
Spinal muscular atrophy (SMA) is an autosomal-recessive neuromuscular disorder representing a continuous spectrum of muscular weakness ranging from compromised neonates to adults with minimal manifestations. Patients show homozygous absence or disease-causing variants of the SMN1 gene $(-/-$ or $0 / 0)$ and in carriers only one copy is absent or mutated $(1 / 0)$. Genetic diagnosis and counseling in SMA present several challenges, including the existence of carriers (2/0) that are undistinguishable of non-carriers (1/1) with current genetic testing methods and the report of patients $(0 / 0)$ with very mild manifestations and even asymptomatic that are discovered when a full symptomatic case appears in the family. Younger asymptomatic siblings of symptomatic SMA patients are usually never tested until adolescence or adult life. However, following regulatory approval of the first tailored treatment for SMA, the prospects for care of these patients have changed. Early testing, including pre-symptomatic newborn screening and confirmation of diagnosis would change proactive measures and opportunities for therapy based in the actual landscape of new treatments. This review discusses the challenges and new perspectives of genetic counseling in SMA.
\end{abstract}

\section{Introduction}

Spinal muscular atrophy [SMA] is an autosomal-recessive neuromuscular disorder characterized by degeneration and loss of alpha-motor neurons in the anterior horn of the spinal cord. SMA is considered one of the commonest causes of infant morbimortality with an estimated incidence of 1/6000-1/10,000 live births [1].

Clinically, SMA patients present in general with some degree of muscle weakness, areflexia, respiratory, and orthopedic problems and are classified into four main groups based on motor milestones achieved and age of onset (Table 1). In type-I SMA patients (Werdnig-Hoffmann form), the disease begins before 6 months and patients usually die before the age of 2 years [2, 3]. Type-II SMA patients (intermediate form) manifest the disease before

Eduardo F. Tizzano

etizzano@ vhebron.net

1 Department of Clinical and Molecular Genetics Hospital Valle Hebron, Medicine Genetics Group VHIR, Barcelona, Spain

2 CIBERER, Barcelona, Spain
18 months of life and they are able to sit but are unable to walk unaided. Type-III SMA patients show a milder form of the disease (Kugelberg-Welander form) after 18 months of life; these patients are able to stand and walk autonomously but often become wheelchair-bound during youth or adulthood. Subgroups for types I-III are considered here (Table 1). Type-IV SMA patients are characterized by onset after the age of 30 years with milder manifestations of muscular weakness. Finally, a fifth class might be considered, including those with minimal clinical manifestations and therefore usually undetected unless a haploidentical sibling shows SMA phenotype (see below last section). Altogether SMA represents a continuous spectrum of phenotypes ranging from very compromised neonates and infants to adults with minimal manifestations [4] (Table 1).

The Survival motor neuron 1 gene (SMN1) has been identified as the SMA disease-determining gene [5] caused by the occurrence of homozygous absence by deletion or gene conversion events $(90 \%)$, hybrid genes $(5 \%)$, or subtle disease-causing variants $(<5 \%)$ [6]. This gene is located in a complex genomic structure with $500-\mathrm{kb}$ duplication at 5q13. As a consequence of this duplication, in the centromeric region of this locus, there is a highly homologous copy of SMN1 and SMN2, which has been described as an 
Table 1 Spinal muscular atrophy classification considering motor milestones achieved and the wide spectrum of manifestations of the disease including asymptomatic cases that are haploidentical to their corresponding more affected siblings (considered as type- $\mathrm{V}$ form)

\begin{tabular}{|c|c|c|c|c|c|c|}
\hline $\begin{array}{l}\text { Main } \\
\text { SMA type }\end{array}$ & Subclassification & Onset & $\begin{array}{l}\text { Milestones } \\
\text { achieved }\end{array}$ & $\begin{array}{l}\text { Evolution/natural } \\
\text { history }\end{array}$ & $\begin{array}{l}\text { Prevalent } \\
\text { SMN2 copies }\end{array}$ & $\begin{array}{l}\text { Representative } \\
\text { references }\end{array}$ \\
\hline I & $\begin{array}{l}\text { Ia (also } \\
\text { referred as } \\
\text { type } 0)^{\mathrm{a}}\end{array}$ & Prenatal & None & $\begin{array}{l}\text { Death in weeks } \\
\text { Contractures } \\
\text { Cardiopathy }\end{array}$ & 1 & [46] \\
\hline I & $\mathrm{Ib}$ & $<3$ months & $\begin{array}{l}\text { Poor or none } \\
\text { cephalic control }\end{array}$ & $\begin{array}{l}\text { Feeding and } \\
\text { respiratory problems } \\
\text { Linear declination } \\
\text { Death after second or } \\
\text { third year of life }\end{array}$ & 2 & {$[2,3]$} \\
\hline I & Ic & $>3$ months & Cephalic control & $\begin{array}{l}\text { Feeding and } \\
\text { respiratory problems } \\
\text { Plateau in first } 2 \text { years }\end{array}$ & 3 & {$[2,3]$} \\
\hline II & IIa & $>6$ months & Sitter & $\begin{array}{l}\text { Scoliosis } \\
\text { May lose sitting } \\
\text { capability }\end{array}$ & 3 & {$[7,25,47]$} \\
\hline II & $\mathrm{IIb}$ & Usually after 12 months & Sitter & $\begin{array}{l}\text { Scoliosis } \\
\text { May stand with } \\
\text { support }\end{array}$ & 3 & {$[7,25,47]$} \\
\hline III & IIIa & Between 18 and 36 months & Walker unaided & $\begin{array}{l}\text { Scoliosis } \\
\text { Earlier loss of walking }\end{array}$ & 3 & [15] \\
\hline III & IIIb & $>3$ years & Walker unaided & Later loss of walking & $3-4$ & {$[15,25]$} \\
\hline IV & None $^{b}$ & Second/third decade of life & Walker unaided & Most of life walking & $3-5$ & {$[44,48]$} \\
\hline V & None & $\begin{array}{l}\text { SMN1 absence with minimal } \\
\text { manifestations or asymptomatic }\end{array}$ & $\begin{array}{l}\text { All major } \\
\text { milestones }\end{array}$ & Complete life walking & $3-5$ & {$[24,40,42,44]$} \\
\hline
\end{tabular}

SMA spinal muscular atrophy, SMN1, 2 Survival motor neuron 1, 2

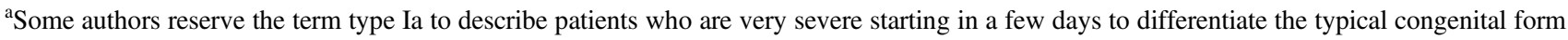
as type 0 . In our Table, we consider type 0 or type Ia as those patients in the extreme category of severity with one SMN2 copy

${ }^{\mathrm{b}} \mathrm{Some}$ authors consider type IV as a type IIIb with adult onset

SMA modifier [5, 7]. Both genes are quite identical with some divergences mainly localized within the 3' end of these genes [8]. A C $>\mathrm{T}$ transition at position +6 of the exon 7 (c.840C >T, NM_000344.3; exons are numbered as in Bürglen et al. [8]) is the only difference in the coding region and is responsible for alternative splicing of this exon. As a consequence most of the SMN2 transcripts lack exon 7 and the protein is incomplete and rapidly degraded. The broad range of phenotypic severity is modified mainly by the number of copies of this "backup" SMN2 gene. However, the correlation is not absolute and other genetic or environmental factors may influence the final phenotype in a patient [7].

Advances into the genetics of SMA have identified therapeutic targets that are now under clinical investigation (www.clinicaltrials.gov). Moreover, the first tailored therapy for SMA has been approved in US and Europe transforming the prospects for care, trajectories of the disease, and evolving of the phenotype of these patients [9]. In this perspective review, we discuss how these advances may influence the genetic counseling approach and the decisionmaking process in SMA families.

\section{The new therapeutic landscape}

Clinical care and follow-up for SMA patients has advanced significantly over the past two decades. This is mainly due to improved proactive standard-of-care measures with the aim to minimize diagnostic delay for early intervention and optimize as much as possible quality of life and independent function [10,11]. These supportive measures mainly include physiotherapy, respiratory care, and nutritional support, which do not affect the underlying biological progression of the disease. As a consequence, in type I patients motor function fails to improve and decline to become permanently ventilator dependent or a final fatal outcome $[2,3,12]$. In the less severe chronic forms, motor achievements may stabilize and later decline at specific ages being stable for long periods until the patients lose a fundamental motor milestone (i.e., autonomous sitting in very weak type-II patients or the walking capacity in type-III patients) [9, 13-15] (Fig. 1). The trajectory of the disease is now changing due to the success of novel therapies to improve motor function in these patients. The concept of SMA as 


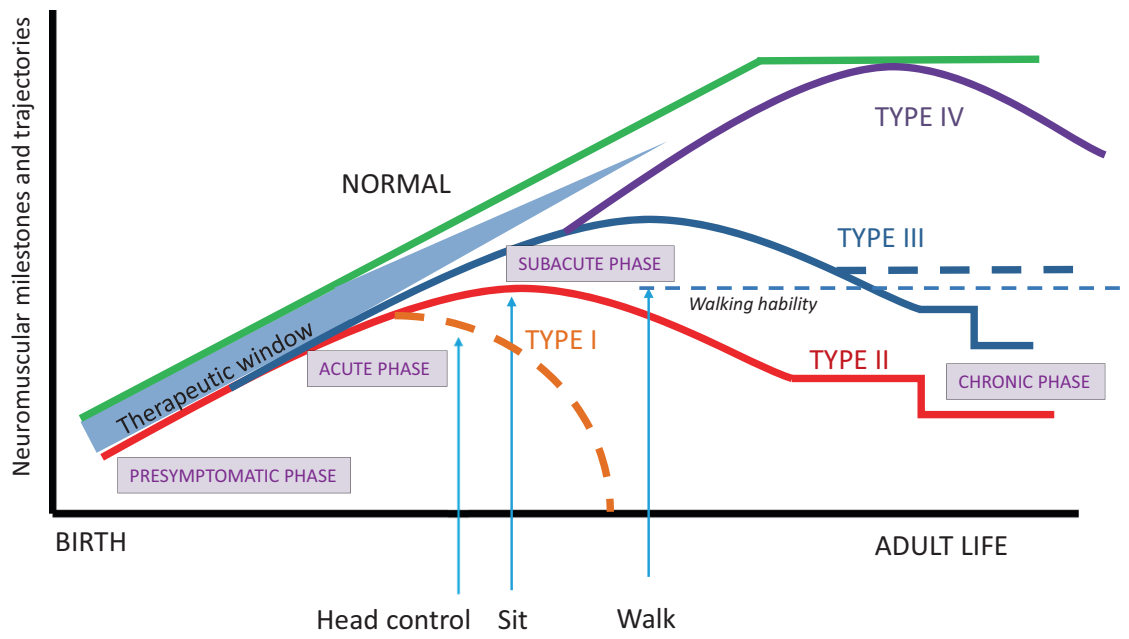

Fig. 1 Neuromuscular milestones and trajectories from birth to adult life in spinal muscular atrophy (SMA) types. SMA patients present a pre-symptomatic phase, which is considered a therapeutic window to initiate the most effective intervention and treatment before substantial motor neuron loss occurs. Type-I disease has an acute phase with linear decline to death if no invasive respiratory intervention is made (dashed orange line). Type-II and -III SMA have a subacute onset in infancy and a late chronic more stable phase. Some type III patients maintain the walking ability for years (thick dashed blue line). Type-

an untreatable disease has now fundamentally evolved with the demonstration in clinical trials that nusinersen $\left[\right.$ Spinraza $\left.{ }^{\mathrm{TM}}\right]$ is effective and is the first approved drug for SMA treatment. Nusinersen is an antisense oligonucleotide that binds specifically a silencer sequence in intron 7 allowing inclusion of exon 7 in the mature mRNA from SMN2 [4]. This mechanism increases the amount of fulllength SMN, the protein that is diminished in patients with SMA. Clinical investigations demonstrate that SMA children can reach developmental milestones, which are never normally achieved in SMA [17], and in later onset patients nusinersen improves motor function [18]. Another advanced approach is gene therapy by self-complementary adeno-associated virus 9, which is still under clinical investigation but with very promising results in the first 15 treated type-I patients [19] and in other clinical trials ongoing. Several other medications are under study making SMA the rare genetic disease with most specific therapeutic options under clinical investigation including small molecules compounds that act as splicing modifiers, neuroprotectors, and myoactivators [www.clinicaltrials.gov]. As orphan drugs, their high cost and different refund policies of health insurance in different countries makes treatment not widely available. This implies a substantial commitment of different guilds such as health authorities and professionals, pharmaceutical industry, curators, and advocacy groups to guarantee equity and access to such treatments.
IV disease appears gradually during adult life. All SMA types can be treated early at pre-symptomatic stages according to the length of their respective and different therapeutic windows and is very likely that these patients will closely follow the green normal line. Treatment in already symptomatic patients may change trajectories with the slopes tending to reach the green normal line depending on each case (onset of disease, onset of treatment) and with new emerging phenotypes. Type-0 trajectories are not represented. Based on [4, 9, 12-16]

\section{Early intervention: toward pre-symptomatic testing and treatment}

Preclinical data in SMA animal models [20] as well as results of clinical trials support the view that the earlier the treatment is initiated, the better the efficacy $[17,19]$. This is observed in the ongoing Nurture trial in which early nusinersen treatment in pre-symptomatic infants prevents the onset of the SMA phenotype and allows for progressive achievements in motor function [21], NCT02386553, [www.clinical.trials.gov].

Pre-symptomatic individuals with SMA can be genetically identified by different situations. (1) Prenatal testing, requested by parents who have previously had an affected child or who are screened as carriers [22]. Much less common is the finding of an extended prenatal screening, even in the absence of any indication [16]; (2) Newborn screening, which is becoming available in some populations [23]; and (3) when one asymptomatic sibling is tested for SMN1 to establish his/her carrier status but shows homozygous deletion as his/her affected sibling [24, 25]. If those subjects are treated pre-symptomatically, the latency period of the disease may be altered in different elements: age of symptom onset, weakness, and acquisition of motor milestones and evolution (Fig. 1). These modifications may range from remaining asymptomatic the rest of his/her life, delay the age of onset of weakness, or changing to an emerging phenotype [9]. 
Table 2 Wilson-Jungner criteria and references in support of their accomplishment in SMA

\begin{tabular}{|c|c|c|}
\hline Criteria & Accomplishment & References \\
\hline 1. The condition sought should be an important health problem & Yes & {$[2,3,30,31]$} \\
\hline $\begin{array}{l}\text { 2. There should be an accepted treatment for patients with } \\
\text { recognized disease }\end{array}$ & Yes & {$[17-19]$} \\
\hline 3. Facilities for diagnosis and treatment should be available & Yes & {$[10,11]$} \\
\hline $\begin{array}{l}\text { 4. There should be a recognizable latent or early } \\
\text { symptomatic stage }\end{array}$ & Yes & {$[16,27,28]$} \\
\hline 5. There should be a suitable test or examination & Yes & {$[23,49,50]$} \\
\hline 6. The test should be acceptable to the population & Yes & {$[51,52]$} \\
\hline $\begin{array}{l}\text { 7. The natural history of the condition, including development } \\
\text { from latent to declared disease, should be adequately } \\
\text { understood }\end{array}$ & Yes & {$[2,3,12-15]$} \\
\hline 8. There should be an agreed policy on whom to treat as patients & Still debatable/ongoing & {$[9,29]$} \\
\hline $\begin{array}{l}\text { 9. The cost of case-finding should be economically balanced in } \\
\text { relation to possible expenditure on medical care as a whole }\end{array}$ & Yes & {$[30,31]$} \\
\hline $\begin{array}{l}\text { 10. Case-finding should be a continuing process and not a "once } \\
\text { and for all" project }\end{array}$ & Yes & {$[9,53]$} \\
\hline
\end{tabular}

SMA spinal muscular atrophy

The strategy that would have a greater impact regarding early detected patients is neonatal screening. In fact, with the impact of new therapies and treatments, a global change in healthcare policies should be done to take a crucial step forward in the approach of this disease. Strong arguments would support the addition of SMA in the newborn screening, considering the criteria proposed by Wilson and Jungner that are widely used to include or refuse a disease in the mentioned screening [26]. These criteria include 10 different items and all of them are virtually met by SMA (Table 2). The first two requisites deserve special attention: (1) the condition sought should be an important health problem, and (2) there should be an accepted treatment for patients with recognized disease.

The annual incidence of SMA is approximately 1/ $6000-10,000$ newborns, not far as the $1-5 / 10,000$ newborns for phenylketonuria or 1/3500 for congenital hypothyroidism, two diseases worldwide included, and clearly higher than methylmalonic acidemia or medium-chain acyl-coenzyme A dehydrogenase deficiency, also included in some newborn screening programs. Regarding the treatment for patients, data proving the efficacy of newly developed drugs, as mentioned previously, would imply the compliance of this criterion.

A genetically confirmed neonatal asymptomatic case should be examined to look for features in the neuromuscular and respiratory phenotype (i.e., hypotonia, fasciculations, hypo-areflexia, paradoxical breathing) and other markers of disease $[16,27,28]$. The gradual implementation of universal neonatal screening would provide more information and experience to categorize each patient to observe the evolution together with the decision making by the family to receive treatment. The latency period to clinical onset and therefore the therapeutic window is larger in chronic type-II and -III forms than in acute type-I SMA and there is a longer evolution of the neuromuscular phenotype with less involvement of other systems or organs [9] (Fig. 1). Decision may be delayed to initiate treatment in some cases and proceed with a careful follow-up (see below) [29]. However, it also should be considered that improved care or proactive care of the positive asymptomatic cases may result in benefit for the clinical impact of the disease.

At present, newborn screening is considered a reasonable initial approach for SMA prevention considering the moving from treat cases with manifesting disease (tertiary prevention) to treat disease in asymptomatic period (secondary prevention). However, it is envisaged that public health in the genomic scenario will result in the consolidation of carrier screening programs in the population (primary prevention) (Fig. 2). When carrier screening programs are implemented, couples have the opportunity to make a decision pre-conceptionally. In those cases in which both are carriers for the same disease, different options might be considered if the couple wants to avoid the disease in their offspring as prenatal testing, preimplantation genetic diagnosis, or gamete donation. These options cause a decrease of the incidence and prevalence of the disease with a substantial impact in the health system, considering the burden of the disease [30,31] and the high cost of new treatments [32]. On the other hand, the availability of an effective treatment for the disease will probably increase the number of couples who may refuse the options mentioned above. Nevertheless, important ethical aspects emerged in these scenarios and genetic counseling should be provided including adequate and clear communication and 


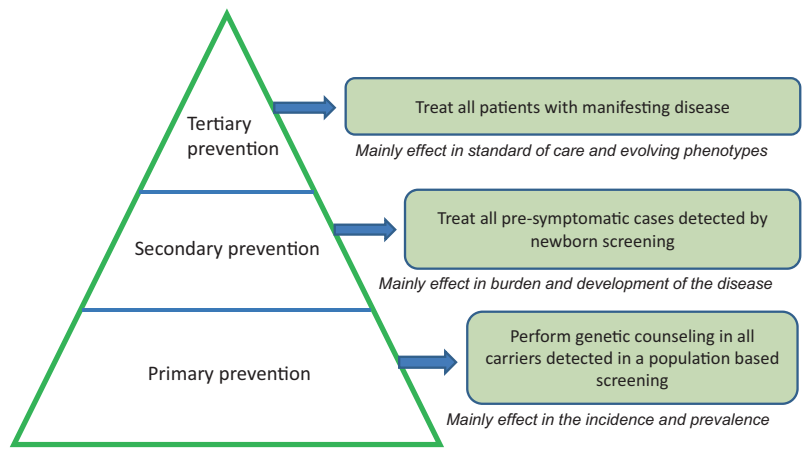

Fig. 2 Epidemiologic evolution and prevention policies in spinal muscular atrophy (SMA). The actual situation of treatment of symptomatic cases when disease is already established (tertiary prevention, with a main effect in standard of care and evolving phenotypes) should change to implement newborn screening to treat patients before symptoms during the therapeutic window (secondary prevention, with a main effect in burden and development of disease). This would allow also detection of other carriers in the family. Public health policies should consider in the near future population carrier testing not only specific to SMA but several other autosomal-recessive conditions (primary prevention). These measures unavoidably will decrease the incidence and the prevalence of the disease in the future

psychological support to manage the expectations of the families.

The availability of effective treatment options includes a strong debate of which pre-symptomatic SMA patients should be treated $[9,29]$. At present, the only predictive marker that correlates in most of the cases with the different phenotypes is the number of $S M N 2$ copies [7]. More than $90 \%$ of the patients with two SMN2 copies will develop the most severe type-I disease starting in the newborn or infant period, whereas patients with four SMN2 copies will be virtually walkers and develop the milder forms even years later. Patients with three $S M N 2$ copies may develop whatever type of disease from type Ic (some cephalic control), type II (sitters), or type III (walkers) (Table 1). No marker yet predicts if a patient with three $S M N 2$ copies will be a non-sitter, a sitter, or a walker [7]. Thus patients with three or four copies involve a difficult decision on when to start the treatment and proactive measures [7, 28, 29]. The actual scenario of treatment will modify the characteristic of the patients in the future, considering emerging phenotypes and updated classifications [9]. At present, most of the prevalent patients are historical with newly symptomatic diagnosed cases and a few pre-symptomatic detected. In the next future, the universal newborn screening is expected to transform this proportion and most of the cases would be treated in the pre-symptomatic period with a new evolving or even normal phenotype, fewer cases resulting from false negative in newborn screening may be detected late when manifesting the disease and none of very few historical will be naive of treatment (Fig. 3). Furthermore, the identification of the disease pre-symptomatically will also lead to the rapid identification of relatives at high risk of being carriers. This situation might be faced by genetic counselors to inform and manage family expectations and reproductive issues.

\section{Genetic counseling in SMA}

\section{Carrier diagnosis}

As an autosomal-recessive disease with a carrier frequency around 1/35-1/60 [1] in European populations, accurate detection of SMA carriers in a family is decisive for adequate genetic counseling. Accordingly, parents of a SMA case are not always carriers and a small proportion of them are considered as de novo or germinal/somatic mosaic cases influencing the final risk for a given couple [33]. Usually SMA carrier testing implies the performance of a quantitative method that detects one copy of $S M N 1$ in classical 1/0 carriers. A small proportion of carriers $(\sim 3-4 \%)$ have two SMN1 copies in cis and none in the other allele (2/0 carriers). However, when an individual presents two $S M N 1$ copies, the current carrier diagnosis methods based on the SMN1 dosage do not allow discrimination between 1/1 noncarriers and 2/0 carriers. In putative carriers within blood relatives, haplotype analysis located in the SMA locus is helpful to define these $2 / 0$ carriers [33]. However, a more difficult genetic counseling situation involves the study of partners of SMA carriers (from the general population) with two SMN1 copies where family tracking of haplotypes is not useful. Although the presence of some intragenic polymorphisms in $S M N 1$ is helpful to categorize a risk group of $2 / 0$ carriers $[34,35]$, their absence in a person with two $S M N 1$ copies does not preclude $2 / 0$ carrier status limiting the utility of this analysis to some populations [35]. Testing of the parents of a partner consultant to exclude the presence of a chromosome with one SMN1 copy is usually confirmatory to interpret the consultant case as $1 / 1$ noncarrier [33, 35] although the cost-effectiveness of this approach should be considered.

\section{Predictive biomarkers of evolution of disease}

The number of $S M N 2$ copies that is detected in a patient is, to date, the most important known phenotypic modifier of the disease, since a higher number of SMN2 copies correlates with higher production of some properly spliced SMN mRNA and thus functional SMN protein levels leading to milder phenotypes. However, this correlation is not absolute and phenotypic discordances occur (Table 3). Patients with one or two SMN2 copies usually develop type-I disease although a few patients present a milder phenotype [7]. The presence of a c.859G $>C$ variant (exclusively to SMN2, NM_017411.3), which is a 


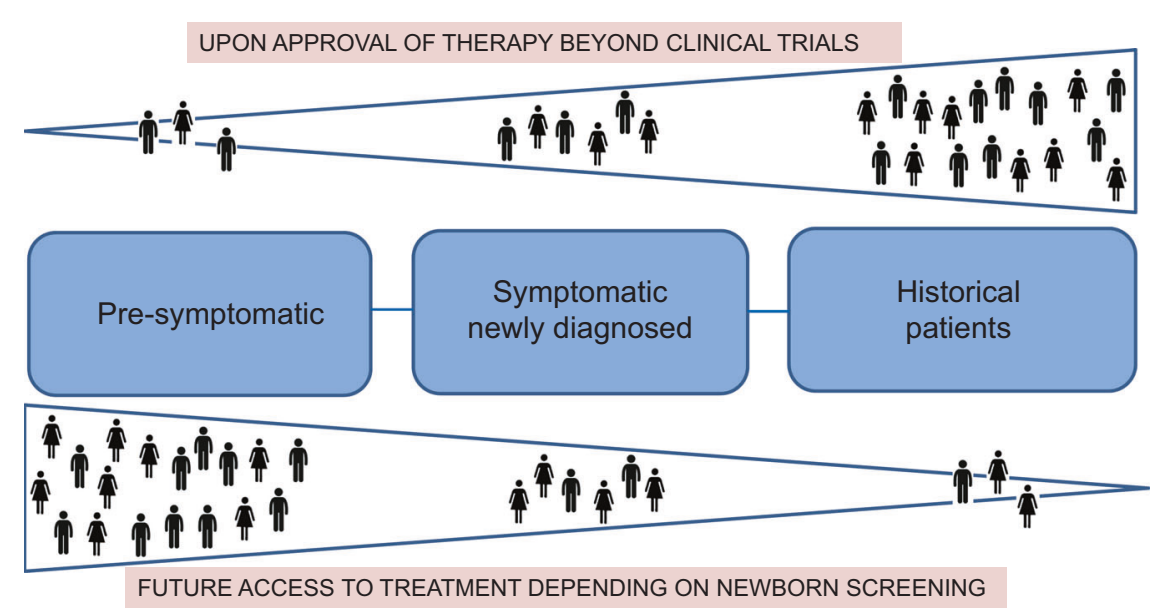

Fig. 3 Changing scenario of access to treatment in spinal muscular atrophy. At present (upper triangle), the new treatments reach fewer pre-symptomatic babies, almost all newly symptomatic cases, and an important number of historical patients. The implementation of universal newborn screening (lower triangle) would modify the proportion and most of the patients will be treated at pre-symptomatic stages, fewer will be newly symptomatic (because of false negative in newborn screening, i.e., disease-causing point mutations), and the vast majority of the historical cases will be already under treatment

Table 3 Phenotypic discordances in SMA according to SMN2 copies

\begin{tabular}{|c|c|c|c|}
\hline Observed discordances & Situation & Possible explanation/cause & References \\
\hline $\begin{array}{l}\text { More severe phenotype than expected by the } S M N 2 \\
\text { copy number }\end{array}$ & $\begin{array}{l}\text { Type-I phenotype and } 3 \\
\text { SMN2 copies }\end{array}$ & Negative modifiers in $S M N 2$ & {$[7,54]$} \\
\hline $\begin{array}{l}\text { Less severe phenotype than expected by the SMN2 } \\
\text { copy number }\end{array}$ & $\begin{array}{l}\text { Type-II or -III phenotype and } 2 \\
\text { SMN } 2 \text { copies }\end{array}$ & Positive modifiers in $S M N 2$ & {$[36-38]$} \\
\hline $\begin{array}{l}\text { Unrelated patients with } 3 \text { SMN2 copies and different } \\
\text { outcome (see also text) }\end{array}$ & $\begin{array}{l}\text { All three main types, mostly } \\
\text { sitters or walkers }\end{array}$ & $\begin{array}{l}\text { Different transcriptional equivalence } \\
\text { of } S M N 2 \text { copies (methylation, } \\
\text { variants, partial deletions) }\end{array}$ & $\begin{array}{l}\text { [7] and } \\
\text { references } \\
\text { therein }\end{array}$ \\
\hline $\begin{array}{l}\text { A haploidentical sibling less affected than his/her } \\
\text { affected sibling or asymptomatic (with SMN1 absence } \\
\text { and the same SMN2 copy number) }\end{array}$ & $\begin{array}{l}\text { Dissimilar achieved motor } \\
\text { milestones or minimal } \\
\text { manifestations or asymptomatic }\end{array}$ & $\begin{array}{l}\text { Genetic/genomic/epigenetic } \\
\text { modifiers }\end{array}$ & {$[24,40,42,44]$} \\
\hline
\end{tabular}

SMA spinal muscular atrophy

positive modifier, accounts for an important proportion of those milder cases [36, 37]. More recently, a $\mathrm{G}>\mathrm{A}$ transition in intron 6 of SMN2, NC_000005.9:g.69372304A $>\mathrm{G}(\mathrm{Chr5}$,hg19), has also been described as a positive modifier [38]. On the other hand, patients with three $S M N 2$ copies may never walk or conversely may walk for several years. Patients with one copy (mostly type Ia or 0 ) or with four copies (mostly types IIIb and 4) are more consistent with the phenotype [7]. Thus SMN2 copy number is a good (but not perfect) predictor of SMA type, albeit it is of no proven value as a marker of ongoing disease activity or response to treatment. For this purpose, other biomarkers such as neurofilaments are under study [39].

\section{Concordant and discordant siblings in SMA families}

Asymptomatic younger siblings are usually not tested until they arrive to the reproductive age to request genetic counseling. Adult siblings of a SMA patient often seek for carrier testing and reproductive counseling. If the sibling under study presents one SMN1 copy, this is confirmatory to be a carrier and testing can be offered to the partner. This apparently simple scenario of carrier testing and genetic counseling become complex when testing an asymptomatic sibling for SMN1 copies and the result is 0 copies of $S M N 1$ as occurs with the affected person in the family [24, 40]. This rather unexpected finding opens the question of what will be the clinical evolution and outcome of this haploidentical sibling and, of course, if proactive measures or therapeutic options should be considered.

Most of these haploidentical sibs cases are detected in families with SMA milder forms in adulthood, and some of these particular siblings are considered as SMA with minimal manifestations or even asymptomatic (see Table 1). All these cases may be the result of different levels of SMN 
protein expression due to the presence of still unknown modifying genetic or environmental factors. Discordant phenotypes in SMA siblings have been reported prior to the identification of SMN1 as causative of disease, and all cases appeared to have some degree of clinical manifestations [41]. After SMN1 discovery, it was noted with surprise that even asymptomatic or unaffected siblings could be homozygously deleted for SMN1 just as their symptomatic brothers or sisters. With a few exceptions, all these cases reported are haploidentical [24, 25, 40, 42 and references therein]. Thus the $S M N 1$ genotype and the number of copies of $S M N 2$ are the same within the siblings of a given family. Interestingly, in most of the families described in these studies, the less affected sibling tends to be a female. It has therefore been proposed that gender-related protective factors may influence the SMA phenotype. Indeed, it has been reported that unaffected $S M N 1$-deleted females exhibited significantly higher expression of plastin 3 (PLS3) than their SMA-affected counterparts [42]. PLS3 is considered a possible gender-specific SMA modifier whose protective effect may not be fully penetrant, thereby pointing toward an interaction with additional factors, such as neurocalcin [43]. However, there are no reported DNA variants in PLS3 that can be applied as predictive of phenotype and discordance is not limited to male-female sibling pairs: it has also been reported in pairs of male siblings and in pairs of female siblings and in cases where females were more severely affected than males [24, 40, 44].

\section{Shall we perform early SMN1 testing in minor asymptomatic siblings?}

Genetic testing needs to be always considered from an ethical perspective given that genetic information is a special sensitive data in terms of confidentiality, privacy, and autonomy, including the right to know and the right not to know.

For these reasons, genetic testing in minors has been even more carefully addressed. While genetic testing to reach a diagnosis of a child clinically manifesting a genetic disease seems straightforward, the situation becomes complex in asymptomatic minors. Recommendations from different boards and institutions agree to only consider genetic testing in asymptomatic minors if the test result would modify their clinical management and, therefore, probably the outcome of the disease.

As stated by the European Society of Human Genetics, pre-symptomatic and predictive testing for conditions that become manifest in adulthood and that cannot be effectively treated or prevented, carrier testing should be discouraged until the person has the maturity and competence to comprehend its implications and, consequently, take an informed decision [45].
Regarding asymptomatic siblings of SMA patients, until now, genetic testing was mainly considered to explore their carrier status for their reproductive planning. Therefore, genetic counseling was offered when they reach reproductive age to ensure that the decision of undergoing a genetic test was taken by themselves with adequate information.

As mentioned before, in some cases, siblings of SMA patients were surprisingly found to be homozygous for a null allele when tested for reproductive risk assessment. Without an effective treatment, advancing this test in childhood would have implied a pre-symptomatic test for a disease that would become manifest later and that could not be effectively treated or prevented and thus not recommended by experts. Nevertheless, the scenario described above has substantially changed since effective treatments are being tested transforming the outcome and prognosis of the disease mainly with an early therapeutic intervention. Automatically, genetic testing for asymptomatic siblings of SMA patients would be reconsidered as a pre-symptomatic genetic testing for conditions with later (even adult) onset in which preventive actions can be initiated before manifestations, modifying the prognosis of the disease. In that case, genetic testing would be justified under the umbrella of the beneficence principle testing, as detecting a double null allele in an asymptomatic sibling of a SMA patient would inevitably activate the consideration of a close follow-up and a possible therapeutic intervention.

The described scenario not only compel us to reconsider genetic counseling approach and testing in apparently asymptomatic siblings but also urge the scientific community to include SMA in neonatal screening, considering the blooming of new therapeutic approaches.

In conclusion, the emergence of new and effective treatments boosts professionals to rethink the paradigm traditionally used to approach genetic diseases to ensure that innovation rapidly impacts on the patients' quality of life.

Acknowledgements This work was partially supported by Grants from Fundación Privada Daniel Bravo Andreu and Fondo de Investigación Sanitaria PI18/00687 to EFT. The authors are indebted to the Genetics working team for the daily sharing of experience and all SMA patients and families for their support, perseverance, and encouragement.

\section{Compliance with ethical standards}

Conflict of interest E.F.T. has received grant support to conduct clinical trials on SMA from Ionis/Biogen and serves as a consultant to Biogen, AveXis, Roche, Biologix, and Cytokinetics. The other author declares that she has no conflict of interest.

Publisher's note: Springer Nature remains neutral with regard to jurisdictional claims in published maps and institutional affiliations.

Open Access This article is licensed under a Creative Commons Attribution 4.0 International License, which permits use, sharing, 
adaptation, distribution and reproduction in any medium or format, as long as you give appropriate credit to the original author(s) and the source, provide a link to the Creative Commons license, and indicate if changes were made. The images or other third party material in this article are included in the article's Creative Commons license, unless indicated otherwise in a credit line to the material. If material is not included in the article's Creative Commons license and your intended use is not permitted by statutory regulation or exceeds the permitted use, you will need to obtain permission directly from the copyright holder. To view a copy of this license, visit http://creativecommons. org/licenses/by/4.0/.

\section{References}

1. Sugarman EA, Nagan N, Zhu H, Akmaev VR, Zhou Z, Rohlfs EM, et al. Pan-ethic carrier screening and prenatal diagnosis for spinal muscular atrophy: clinical laboratory analysis of $>72,400$ specimens. Eur J Hum Genet. 2012;20:27-32.

2. Finkel RS, McDermott MP, Kaufmann P, Darras BT, Chung WK, Sproule DM, et al. Observational study of spinal muscular atrophy type I and implications for clinical trials. Neurology. 2014;83:810-7.

3. Kolb SJ, Coffey CS, Yankey JW, Krosschell K, Arnold WD, Rutkove SB, et al. Natural history of infantile-onset spinal muscular atrophy. Ann Neurol. 2017;82:883-91.

4. Talbot K, Tizzano EF. The clinical landscape for SMA in a new therapeutic era. Gene Ther. 2017;24:529-33.

5. Lefebvre S, Bürglen L, Reboullet S, Clermont O, Burlet P, Viollet $\mathrm{L}$, et al. Identification and characterization of a spinal muscular atrophy- determining gene. Cell. 1995;80:155-65.

6. Alías L, Bernal S, Fuentes-Prior P, Barceló MJ, Also E, MartínezHernández R, et al. Mutation update of spinal muscular atrophy in Spain: molecular characterization of 745 unrelated patients and identification of four novel mutations in the SMN1 gene. Hum Genet. 2009;125:29-39.

7. Calucho M, Bernal S, Alias L, March F, Venceslá A, RodríguezÁlvarez FJ, et al. Correlation between SMA type and SMN2 copy number revisited: an analysis of 625 unrelated Spanish patients and a compilation of 2,834 reported cases. Neuromuscul Disord. 2018;28:208-15.

8. Bürglen L, Lefebvre S, Clermont O, Burlet P, Viollet L, Cruaud $\mathrm{C}$, et al. Structure and organization of the human survival motor neurone [SMN] gene. Genomics. 1996;32:479-82.

9. Tizzano EF, Finkel RS. Spinal muscular atrophy: a changing phenotype beyond the clinical trials. Neuromuscul Disord. 2017;27:883-9.

10. Mercuri E, Finkel RS, Muntoni F, Wirth B, Montes J, Main M, et al. Diagnosis and management of spinal muscular atrophy: Part 1: Recommendations for diagnosis, rehabilitation, orthopedic and nutritional care. Neuromuscul Disord. 2018;28:103-15.

11. Finkel RS, Mercuri E, Meyer OH, Simonds AK, Schroth MK, Graham RJ, et al. Diagnosis and management of spinal muscular atrophy: Part 2: Pulmonary and acute care; medications, supplements and immunizations; other organ systems; and ethics. Neuromuscul Disord. 2018;28:197-207.

12. De Sanctis R, Coratti G, Pasternak A, Montes J, Pane M, Mazzone ES, et al. Developmental milestones in type I spinal muscular atrophy. Neuromuscul Disord. 2016;26:754-9.

13. Kaufmann P, McDermott MP, Darras BT, Finkel RS, Sproule DM, Kang PB, et al. Prospective cohort study of spinal muscular atrophy types 2 and 3. Neurology. 2012;79:1889-97.

14. Mercuri E, Finkel R, Montes J, Mazzone ES, Sormani MP, Main $M$, et al. Patterns of disease progression in type 2 and 3 SMA: implications for clinical trials. Neuromuscul Disord. 2016;26:126-31.

15. Zerres K, Rudnik-Schöneborn S. Natural history in proximal spinal muscular atrophy. Clinical analysis of 445 patients and suggestions for a modification of existing classifications. Arch Neurol. 1995;52:518-23.

16. Swoboda KJ, Prior TW, Scott CB, McNaught TP, Wride MC, Reyna SP, et al. Natural history of denervation in SMA: relation to age, SMN2 copy number, and function. Ann Neurol. 2005;57:704-12.

17. Finkel RS, Mercuri E, Darras BT, Connolly AM, Kuntz NL, Kirschner J, et al. Nusinersen versus sham control in infantileonset spinal muscular atrophy. N Engl J Med. 2017;377:1723-32.

18. Mercuri E, Darras BT, Chiriboga CA, Day JW, Campbell C, Connolly AM, et al. Nusinersen versus sham control in later-onset spinal muscular atrophy. N Engl J Med. 2018;378:625-35.

19. Mendell JR, Al-Zaidy S, Shell R, Arnold WD, Rodino-Klapac LR, Prior TW, et al. Single-dose gene-replacement therapy for spinal muscular atrophy. N Engl J Med. 2017;377:1713-22.

20. Foust KD, Wang X, Mcgovern VL, Braun L, Bevan AK, Haidet $\mathrm{AM}$, et al. Rescue of the spinal muscular atrophy phenotype in a mouse model by early postnatal delivery of SMN. Nat Biotechnol. 2010;28:271-4.

21. Bertini E, Hwu W-L, Reyna SP, Farwell W, Gheuens S, Sun P, et al. Efficacy and safety of nusinersen in infants with presymptomatic spinal muscular atrophy [SMA]: Interim results from the NURTURE study. Eur J Paediatr Neurol. 2017;21:e14.

22. Cuscó I, Barceló MJ, Soler C, Parra J, Baiget M, Tizzano E. Prenatal diagnosis for risk of spinal muscular atrophy. BJOG. 2002;109:1244-9.

23. Chien YH, Chiang SC, Weng WC, Lee NC, Lin CJ, Hsieh WS, et al. Presymptomatic diagnosis of spinal muscular atrophy through newborn screening. J Pediatr. 2017;190:124-9.

24. Bernal S, Also-Rallo E, Martínez-Hernández R, Alías L, Rodríguez-Alvarez FJ, Millán JM, et al. Plastin 3 expression in discordant spinal muscular atrophy (SMA) siblings. Neuromuscul Disord. 2011;21:413-9.

25. Medrano S, Monges S, Gravina LP, Alías L, Mozzoni J, Aráoz $\mathrm{HV}$, et al. Genotype-phenotype correlation of SMN locus genes in spinal muscular atrophy children from Argentina. Eur J Paediatr Neurol. 2016;60:723-8.

26. Wilson JM, Jungner YG. [Principles and practice of mass screening for disease]. Bol Oficina Sanit Panam. 1968;65:281-393.

27. Finkel RS. Electrophysiological and motor function scale association in a pre-symptomatic infant with spinal muscular atrophy type I. Neuromuscul Disord. 2013;23:112-5.

28. Tizzano EF, Zafeiriou D. Prenatal aspects in spinal muscular atrophy: from early detection to early presymptomatic intervention. Eur J Paediatr Neurol. 2018;22:944-50.

29. Glascock J, Sampson J, Haidet-Phillips A, Connolly A, Darras B, Day J, et al. Treatment algorithm for infants diagnosed with spinal muscular atrophy through newborn screening. J Neuromuscul Dis. 2018;5:145-58.

30. Klug C, Schreiber-Katz O, Thiele S, Schorling E, Zowe J, Reilich $\mathrm{P}$, et al. Disease burden of spinal muscular atrophy in Germany. Orphanet J Rare Dis. 2016;11:58.

31. López-Bastida J, Peña-Longobardo LM, Aranda-Reneo I, Tizzano E, Sefton M, Oliva-Moreno J. Social/economic costs and healthrelated quality of life in patients with spinal muscular atrophy [SMA] in Spain. Orphanet J Rare Dis. 2017;12:141.

32. King NMP, Bishop CE. New treatments for serious conditions: ethical implications. Gene Ther. 2017;24:534-8.

33. Alías L, Barceló MJ, Bernal S, Martínez-Hernández R, Also-Rallo $\mathrm{E}$, Vázquez $\mathrm{C}$, et al. Improving detection and genetic counseling 
in carriers of spinal muscular atrophy with two copies of the SMN1 gene. Clin Genet. 2014;85:470-5.

34. Luo M, Liu L, Peter I, Zhu J, Scott SA, Zhao G, et al. An Ashkenazi Jewish SMN1 haplotype specific to duplication alleles improves pan-ethnic carrier screening for spinal muscular atrophy. Genet Med. 2014;16:149-56.

35. Alías L, Bernal S, Calucho M, Martínez E, March F, Gallano P, et al. Utility of two SMN1 variants to improve spinal muscular atrophy carrier diagnosis and genetic counselling. Eur J Hum Genet. 2018;26:1554-7.

36. Prior TW, Krainer AR, Hua Y, Swoboda KJ, Snyder PC, Bridgeman SJ, et al. A positive modifier of spinal muscular atrophy in the SMN2 gene. Am J Hum Genet. 2009;85:408-13.

37. Bernal S, Alías L, Barceló MJ, Also-Rallo E, Martínez-Hernández $\mathrm{R}$, Gámez J, et al. The c.859>C variant in the SMN2 gene is associated with types II and III SMA and originates from a common ancestor. J Med Genet. 2010;47:640-2.

38. Wu X, Wang SH, Sun J, Krainer AR, Hua Y, Prior TW. A-44G transition in SMN2 intron 6 protects patients with spinal muscular atrophy. Hum Mol Genet. 2017;26:2768-80.

39. Darras B, Crawford T, Finkel R, Mercuri E, De Vivo D, Oskoui M, Tizzano E, et al. Neurofilament as a potential biomarker for spinal muscular atrophy. Ann Clin Transl Neurol. 2019. https:// doi.org/10.1002/acn3.779.

40. Jedrzejowska M, Borkowska J, Zimowski J, Kostera-Pruszczyk A, Milewski M, Jurek M, et al. Unaffected patients with a homozygous absence of the SMN1 gene. Eur J Hum Genet. 2008;16:930-4.

41. Bouwsma G, Leschot NJ. Unusual pedigree patterns in seven families with spinal muscular atrophy; further evidence for the allelic model hypothesis. Clin Genet. 1986;30:145-9.

42. Oprea GE, Krober S, McWhorter ML, Rossoll W, Müller S, Krawczak M, et al. Plastin 3 is a protective modifier of autosomal recessive spinal muscular atrophy. Science. 2008;320:524-7.

43. Riessland M, Kaczmarek A, Schneider S, Swoboda KJ, Löhr H, Bradler C, et al. Neurocalcin delta suppression protects against spinal muscular atrophy in humans and across species by restoring impaired endocytosis. Am J Hum Genet. 2017;100: 297-315.

44. Cusco I, Lopez E, Soler-Botija C, Barcelo MJ, Baiget M, Tizzano EF. A genetic and phenotypic analysis in Spanish spinal muscular atrophy patients with c.399_402del AGAG, the most frequently found subtle mutation in the SMN1 gene. Hum Mutat. 2003;22:136-43.

45. Borry P, Evers-Kiebooms G, Cornel MC, Clarke A, Dierickx K. Public and Professional Policy Committee [PPPC] of the European Society of Human Genetics [ESHG]. Genetic testing in asymptomatic minors: background considerations towards ESHG Recommendations. Eur J Hum Genet. 2009;17:711-9.

46. Grotto S, Cuisset JM, Marret S, Drunat S, Faure P, AudebertBellanger $\mathrm{S}$, et al. Type 0 spinal muscular atrophy: further delineation of prenatal and postnatal features in 16 patients. J Neuromuscul Dis. 2016;3:487-95.

47. Wadman R, Stam M, Gijzen M, Lemmink HH, Snoeck IN, Wijngaarde CA, et al. Association of motor milestones, SMN2 copy and outcome in spinal muscular atrophy types 0-4. J Neurol Neurosurg Psychiatry. 2017;88:365-7.

48. Wirth B, Brichta L, Schrank B, Lochmüller H, Blick S, Baasner A, et al. Mildly affected patients with spinal muscular atrophy are partially protected by an increased SMN2 copy number. Hum Genet. 2006;119:422-8.

49. Taylor JL, Lee FK, Yazdanpanah GK, Staropoli JF, Liu M, Carulli JP, et al. Newborn blood spot screening test using multiplexed real-time PCR to simultaneously screen for spinal muscular atrophy and severe combined immunodeficiency. Clin Chem. 2015;61:412-9.

50. Kraszewski JN, Kay DM, Stevens CF, Koval C, Haser B, Ortiz V, et al. Pilot study of population-based newborn screening for spinal muscular atrophy in New York state. Genet Med. 2018;20:608-13.

51. Boardman FK, Young PJ, Griffiths FE. Newborn screening for spinal muscular atrophy: the views of affected families and adults. Am J Med Genet A. 2017;173:1546-61.

52. Boardman FK, Sadler C, Young PJ. Newborn genetic screening for spinal muscular atrophy in the UK: the views of the general population. Mol Genet Genomic Med. 2018;6:99-108.

53. Phan HC, Taylor JL, Hannon H, Howell R. Newborn screening for spinal muscular atrophy: anticipating an imminent need. Semin Perinatol. 2015;39:217-29.

54. Hauke J, Riessland M, Lunke S, Eyüpoglu IY, Blümcke I, El-Osta A, et al. Survival motor neuron gene 2 silencing by DNA methylation correlates with spinal muscular atrophy disease severity and can be bypassed by histone deacetylase inhibition. Hum Mol Genet. 2009;18:304-17. 